\title{
Lutzomyia longipalpis abundance in the city of Posadas, northeastern Argentina: variations at different spatial scales
}

\author{
María Soledad Santini' ${ }^{1 /}$, María Soledad Fernández ${ }^{1,2}$, Adriana Alicia Pérez ${ }^{3}$, \\ Adolfo Enrique Sandoval ${ }^{4}$, Oscar Daniel Salomón ${ }^{2,5}$ \\ ${ }^{1}$ Centro Nacional de Diagnóstico e Investigaciones Endemo-epidemicas, \\ Administración Nacional de Laboratorios e Institutos de Salud, Buenos Aires, Argentina \\ ${ }^{2}$ Consejo Nacional de Investigaciones Científicas y Técnicas, Buenos Aires, Argentina ${ }^{3}$ Departamento de Ecología, \\ Genética y Evolución, Facultad de Ciencias Exactas y Naturales, Universidad de Buenos Aires, Buenos Aires, Argentina \\ ${ }^{4}$ Instituto Municipal de Vigilancia y Control de Vectores, Municipalidad de Posadas, Misiones, Argentina \\ ${ }^{5}$ Instituto Nacional de Medicina Tropical, Puerto Iguazú, Misiones, Argentina
}

The distribution of Lutzomyia longipalpis is heterogeneous with a pattern of high abundance areas (HAAs) embedded in a matrix of low abundance areas (LAAs). The objective of this study was to describe the variability in the abundance of $\mathrm{Lu}$. longipalpis at two different spatial levels and to analyse the relationship between the abundance and multiple environmental variables. Of the environmental variables analysed in each household, the condition that best explained the differences in vector abundance between HAA-LAA was the variable "land_grass", with greater average values in the peridomestic environments within the LAA, and the variables "\#sp tree", "\#pots" and "dist_water" that were higher in the HAA. Of the environmental variables analysed in the patches, the variable "unpaved_streets" was higher in the LAAs and the variable "prop_inf_dogs" was higher in the HAAs. An understanding of the main environmental variables that influence the vector distribution could contribute to the development of strategies for the prevention and control of visceral leishmaniasis (VL). This is the first work in which environmental variables are analysed at the micro-scale in urban areas at the southern edge of the current range of Lu. longipalpis. Our results represent a significant contribution to the understanding of the abundance of the vector in the peridomestic habitats of the region.

Key words: Lutzomyia longipalpis - visceral leishmaniasis - spatial variation

Visceral leishmaniasis (VL) in America is caused by the protozoan Leishmania infantum (syn. chagasi) (Cunha \& Chagas 1937, Grimaldi et al. 1989) and the main vector of this parasite is Lutzomyia longipalpis. Lu. longipalpis has been identified as the vector of $L$. infantum in both urban and suburban environments (Lainson \& Rangel 2005) with dogs (Canis familiaris), serving as the main reservoir of infection in the urban settings (Lainson 1989). The increased density and abundance of vectors, reservoirs and parasites in urban scenarios has contributed to the development of epidemic outbreaks, with VL cycling between urban and suburban settings (Grimaldi et al. 1989). VL is now a serious public health problem in America because certain vector species have rapidly adapted to anthropic environments and have settled in peridomestic habitats (Amóra et al. 2009). Although many reports have described the establishment of the urban/suburban cycle, the variables that modulate its permanence remain unknown (Cerbino Neto et al. 2009, Harhay et al. 2011).

The spatial structure of $L u$. longipalpis abundance and its association with the environment are related to

Financial support: ANLIS, Secretaria de Calidad de Vida de la Municipalidad de Posadas, Misiones, Argentina

+ Corresponding author: mariasoledadsantini@gmail.com

Received 14 November 2011

Accepted 15 February 2012 the population dynamics and temporal persistence of the vector, as observed in many other animal populations (Wiens et al. 1993, Ellner 2001), and all of these factors influence the epidemiology of the vector-borne disease. Werneck (2008) proposed that the study of the spatial structure of VL requires approaches that take into account the heterogeneity of the vector distribution and the structure of the variables included in the analysis because in urban environments, both the vector and the risk factors show spatial heterogeneities temporal and spatial dynamics epidemiologies. Recent studies have suggested that the distribution of Lu. longipalpis is heterogeneous and distributed in "source populations" (Salomón et al. 2004) scattered throughout a city in a pattern of high abundance areas (HAA) across a matrix of low abundance areas (LAA), which is consistent with a metapopulation structure (Fernández et al. 2010).

Many environmental variables have been suggested to the risk of urban VL transmission and Lu. longipalpis abundance, such as those associated with unplanned urbanisation and high population densities, as well as other sociodemographic factors (Grimaldi \& Tesh 1993, Oliveira et al. 2006a, Mestre \& Fontes 2007, Rangel \& Vilela 2008, Fernández et al. 2010, Saraiva et al. 2011). Henhouses, chickens and other domestic animals, fruit trees, tree coverage, poor sanitation and a low socioeconomic level have also been associated with sandfly colonisation and the abundance of breeding sites (Sherlock 1996, Alexander et al. 2002, Costa et al. 2005, Oliveira et al. 2003, 2006b, Fernández et al. 2010). Al- 
though there has been a recent focus on urban VL in South America, there is little information regarding the influence of spatial variables at different scales together with environmental and climatic variables on the population of $\mathrm{Lu}$. longipalpis. Thus, the objective of this study was to describe the variability in the abundance of Lu. longipalpis at two different spatial levels and to analyse the vector abundance relationship with the environmental variables. An understanding of the variables that influence the vector distribution in this scenario could contribute to the development of strategies for the prevention and control of VL in urban and suburban areas in the study region.

\section{MATERIALS AND METHODS}

Study area - The city of Posadas $\left(27^{\circ} 23^{\prime} \mathrm{S} 55^{\circ} 53^{\prime} \mathrm{W}\right.$, $120 \mathrm{~m}$ above sea level) is the capital of the Province of Misiones on the northeastern border of Argentina. The Parana River separates Posadas from Encarnación, Paraguay. The city was originally part of the Paranaense Forest, which is a subtropical humid forest of the Amazonian domain (Cabrera 1971) with a mean annual temperature of $21.9^{\circ} \mathrm{C}$ and a mean annual rainfall of 1.914 .2 $\mathrm{mm}$ (2005-2009) (INDEC 2009). Posadas is the most populated city within the province and has greater than 320,000 inhabitants (INDEC 2010).

Entomological sampling - The phlebotomine sandflies were captured using CDC light minitraps operating (Sudia \& Chamberlain 1962) from 05.00 pm-09.00 am for two consecutive nights in each sampling site from November-January 2009. The sites were selected according to the 11 HAAs and the matrix of LAAs previously described by Fernández et al. (2010). From each of the 11 HAA patches and 11 LAA patches, three-10 randomly selected houses were sampled according to the logistic and demographic opportunities. Traps were placed in 73 and 77 houses in the HAAs and LAAs, respectively. Each trap was located in a house that fulfils the "worst scenario" criteria and had a peridomestic environment that was most likely to have phlebotomine sandflies (Feliciangeli et al. 2006, Correa Antonialli et al. 2007).

All phlebotomine sandflies were dried and preserved prior to processing. The specimens were cleared with lacto-phenol and identified according to Galati (2003) with the aid of a microscope (40X magnification). The geoposition of each site with the city of Posadas was determined. The abundance of Lu. longipalpis was estimated based on the number of Lu. longipalpis that were captured in each trap per night.

Environmental variables - Environmental variables that could potentially affect the abundance of $\mathrm{Lu}$. longipalpis were measured by direct observation in the houses and HAA-LAA patches. A total of 14 environmental characteristics were recorded at the household level (150 sampled houses) and five environmental characteristics were recorded for each of the HAALAA patches (22 areas) (Table I). All of the dogs in each patch were tested for $L$. infantum infection using an rK39 test (KalazarDetect ${ }^{\circledR}$, InBios, Seattle, WA) and the ratio of $r K 39+\operatorname{dogs}$ to the total number of tested dogs was calculated. The environmental characteristics were selected based on a review of the vector biology and VL risk literature (Table I) (Gontijo \& Melo 2004, Costa et al. 2005, Lainson \& Rangel 2005, Oliveira et al. 2006a, b, Mestre \& Fontes 2007, Fernández et al. 2010). The characteristics that showed low spatial variability in the analysis were discarded.

Data analysis - To compare the number of Lu. longipalpis specimens in HAAs and LAAs and to estimate the variation between patches, houses and night studies (error), we performed a nested ANOVA. To determine the environmental variables that best explained the differences in vector abundance between the houses and the HAA and LAA patches, we computed an MANOVA/ Discriminant analysis (Quinn \& Keough 2002). The association between the total abundance per trap-night and the abundance of males and females was computed using

\section{TABLE I}

Environmental variables analyzed to explain

Lutzomyia longipalpis abundance recorded in each house and in each high abundance areas and low abundance areas patch

\begin{tabular}{cc}
\hline Variables & $\begin{array}{c}\text { Variables } \\
\text { names }\end{array}$ \\
\hline
\end{tabular}

\section{Houses $^{a}$}

Surface of bare soil or covered with grass in land_grass square metre

Area in the courtyard covered by cement floor in square metre

Distance from house to watercourse in metres

Surface of uncovered soil in square metre

Number of plant-pots

cement

Number of dogs

Number of chickens

Surface covered by vegetation in square metre

Number of tree species

Number of shrub species

Number of plant species

Number of trees

dist_water

m_land

\#pots

\#dogs_houses

\#chickens

veg_m

\#sp tree

\#sp shurb1

\#sp plants

\#tree

Diameter of the trunk of the largest tree in metres diam_trunk

Diameter of the tree top of largest tree in metres diam_tree top

$$
\text { Patches }
$$

Surface covered by vegetation, in square metres $^{b} \quad$ veg_density Number of unpaved streets by patches ${ }^{b}$

Watercource distance measured from the centre of the patch in metres ${ }^{b}$

Number of dogs in the patch ${ }^{a}$

Proportion of infected dogs $(\mathrm{rK} 39+)^{a}$ unpaved_streets ws_dist \#dogs_patches prop_inf_dogs

$a$ : field records surveyed simultaneously with the trapping sessions; $b$ : data computed on a Google Earth ${ }^{\mathrm{TM}}$ satellite image (13 September 2009) (altitude $1.62 \mathrm{~km}$ ). 
Spearman's correlation coefficient for all of the positive traps. A $p$ value of $<0.05$ was considered indicative of a significant difference.

\section{RESULTS}

A total of 1,321 phlebotomine sandflies were captured; all flies were of the species Lu. longipalpis (range 0-478 individuals) and the male:female ratio was 5:35. The total abundance showed a positive correlation with the abundance of males $\left(r_{\mathrm{s}}=0.93 \mathrm{p}<0.05\right)$ and females and $(\mathrm{rs}=0.80 \mathrm{p}<0.05)(\mathrm{n}=36)$ correlation of total abundance. The HHA patches (range 0-512) showed a greater abundance of Lu. longipalpis than the LAA patches (range 0-75) with a $\mathrm{p}=0,0009$; the average $L u$. longipalpis abundance and it standard derivation in HAA and the average Lu. longipalpis abundance and SD in LAA were 8.32;42.3 and 0.65;5.25, respectively. The variation in the average abundance of Lu. longipalpis was recorded for households within the same square ( $\mathrm{p}$ $<0.05 ; 72 \%$ of the total specified variability) and for different sampling nights within the same household (25\% of the total specified variability). Patches in the HAA and LAA did not contribute significantly to the Lu. longipalpis abundance variability $(\mathrm{p}>0.05)$.

Recorded for each household, the scenario that best explained the differences between HAA-LAA vector abundance was the scenario that included the variable "land_grass", with greater average values in peridomestic environments for LAAs and the variables "\#sp tree", "\#pots" and "dist water" (Table I), which were higher in HAAs (MANOVA $\mathrm{p}<0.0001$ ) (Table II).

When considering the variables recorded within each patch, we found that the analysed environmental variable "unpaved_streets" was higher in the LAAs, whereas the variable "prop_inf_dogs" was higher in the HAAs $(\mathrm{p}=0.01)($ Table II).

\section{DISCUSSION}

Fernández et al. (2010) found that the abundance of Lu. longipalpis was not homogeneously distributed throughout the city of Posadas and patches of high and low abundance were identified. Here, we analysed these areas of high and low abundance that were defined by Fernández et al. (2010) and found that the presence of vectors in these areas was mainly determined by the environmental factors of the studied households and not by the spatial scale of the patches or the variation between samples collected during different nights. We also confirmed that the differences in vector abundance in these areas were persistent over time during 2007-2009.

The analytical approach used here allowed us to study the environmental variables that best explained the differences between HAAs-LAAs at two different scales (patches and houses) and to study the contributions of patches, houses and sampling nights to the variations in the abundance of Lu. longipalpis. These results provide information that explains the heterogeneous distribution observed for this vector in urban areas (Fernández et al. 2010). Salomón and Quintana (2011) defined the different spatial scales for eco-epidemiological studies of vector-borne diseases as micro and meso-scales. The smallest scale, the micro-scale, focuses on the main sampling area with a range dependent on the object of study and examines variables that include the autonomous flight of the vector, mean exposed surface of available reservoirs and sites of human activity. The meso-scale involves the study of variations that are associated with changes in the vector population, although its consequences are also registered in the micro-scale. According to these definitions, the results of this work show that at a micro-scale, soil and/or grass surfaces that are exposed to sunlight and no shade and therefore less humid are associated with peridomestic environments with a low abundance of Lu. longipalpis. In contrast, environments with heavy, diverse vegetation that provides shaded, moist soil and a source of carbohydrates for the vectors show an increased abundance of Lu. longipalpis. An increase in vector abundance also occurs in peridomestic environments with a high number of pots that may be humid, provides a source of carbohydrates for the vectors and may also be buffered from high variations in temperature. Pots might also serve as alternative breeding sites

TABLE II

Variables that best explain the differences between high abundance areas (HAA) and low abundance areas (LAA) at houses and patches (multivariate analysis of variance and discriminant analysis)

\begin{tabular}{lccccc}
\hline & & \multicolumn{2}{c}{ HAA } & LAA \\
\cline { 3 - 5 } Level & Variable & Average & Rank/SD & Average & Rank/SD \\
\hline \multirow{2}{*}{ Houses } & land_grass & 164.07 & $(10: 535) / 115.23$ & 222.59 & $(0: 1.400) / 202.97$ \\
& \#pots & 6.50 & $(0: 50) / 12.37$ & 1.81 & $(0: 30) / 5.32$ \\
& \#sp tree & 3.33 & $(0: 7) / 1.99$ & 2.33 & $(0: 9) / 1.88$ \\
Patches & dist_water & 1.386 .48 & $(0: 3.320) / 142.64$ & 557.96 & $(10: 3900) / 1.008 .46$ \\
& unpaved_streets & 1.64 & $(0: 4) / 1.91$ & 2.36 & $(0: 4) / 1.80$ \\
& prop_inf_dogs & 4.73 & $(1: 8) / 2.20$ & 3.00 & $(0: 9) / 2.79$ \\
\hline
\end{tabular}

SD: standard derivation. 
for Lu. longipalpis, as reported for other insects (Mestre et al. 2001) in medium to highly populated urban areas.

When considering the "dist_water" variable, it would be expected that areas closer to a body of water would have more moisture and, as a result, a higher abundance of vectors. However, this effect was not observed at the micro-scale. This finding could be because at this level, the moisture necessary for the breeding of the vector is provided by small water bodies or dark and protected micro-habitats closer to the breeding area, such as the damp areas found in pots (Mestre et al. 2001) or near leaking faucets or rain discharge tubes, rather than larger water bodies, such as rivers or creeks. Accordingly, the proximity to water also did not affect the abundance of Lu. longipalpis at the meso-scale, which is in contrast to the effect reported by Salomón and Quintana (2011).

However the results of this present study were not conclusive at the meso-scale, for several possible reasons: the small sample size was limited by the total number of HAA patches present in the city (Fernández et al. 2010), the variables studied at the meso-scale were not shown to influence the phlebotomine population and the abundance of vectors is determined at micro-scale rather than the meso-scale. However, it was possible to analyse the spatial dynamics of the transmission of VL at the mesoscale based on the greater proportion of rK39+ dogs in areas with a higher abundance of Lu. longipalpis.

This is the first study in which environmental variables are analysed at the micro-scale in urban areas along the southern margin of the current distribution of Lu. longipalpis. Our results represent a significant contribution to the understanding the abundance of the vector in the peridomestic habitats of the region.

Because the application of insecticides has not yet shown a long-term effect on vector abundance (Santini et al. 2010), there is a need to broaden our knowledge of the natural breeding sites of Lu. longipalpis (Lainson \& Rangel 2005). In addition, although permanent monitoring at the micro-scale may appear to be less pragmatic than a remote meso-scale monitoring, the results of this work support the concept that environmental management at the micro-scale can be effective. Given that this scale best defines the variability of the vector abundance, micro-scale prevention and control strategies could be designed and utilised in conjunction with environmental management. The consideration of the variables of "surface of bare soil or covered with grass", "\#sp tree" and "\#pots" as possible contributors to vector abundance in these areas could also lower the risk of transmission in dogs and humans in the urban or suburban areas of the region.

\section{ACKNOWLEDGEMENTS}

To Dra Lilian Tartaglino, from the Secretary of Quality of Life of the City of Posadas, and members of the Vector Laboratory, for the support, logistics and interest to redeem the problems of the region, to the True English Institute, for the language revision, and to the neighbours of the city of Posadas, for opening their houses.

\section{REFERENCES}

Alexander B, de Carvalho RL, McCallum H, Pereira MH 2002. Role of the domestic chicken (Gallus gallus) in the epidemiology of urban visceral leishmaniasis in Brazil. Emerg Infect Dis 8: 1480-1485.

Amóra SSA, Bevilaqua CML, Feijó FMC, Alves ND, Maciel MV 2009. Control of phlebotomine (Diptera: Psychodidae) leishmaniasis vectors. Neotrop Entomol 38: 303-310.

Cabrera AL 1971. Fitogeografía de la Republica Argentina. Bol Soc Argent Bot 16: 1-42.

Cerbino Neto J, Werneck GL, Costa CHN 2009. Factors associated with the incidence of urban visceral leishmaniasis: an ecological study in Teresina, Piauí state, Brazil. Cad Saude Publica 25: 1543-1551.

Correa Antonialli SA, Torres TG, Paranhos Filho AC, Tolezano JE 2007. Spatial analysis of American visceral leishmaniasis in Mato Grosso do Sul state, Central Brazil. J Infect 54: 509-514.

Costa CH, Werneck GL, Rodrigues Jr L, Santos MV, Araujo IB, Moura LS, Moreira S, Gomes RB, Lima SS 2005. Household structure and urban services: neglected targets in the control of visceral leishmaniasis. Ann Trop Med Parasitol 99: 229-236.

Cunha AM, Chagas E 1937. New species of protozoa of the genus Leishmania pathogenic to man Leishmania chagasi n. sp - previous note. Hosp 11: 3-9.

Ellner SP 2001. Habitat structure and population persistence in an experimental communit. Nature 412: 538-543.

Feliciangeli MD, Delgado O, Suarez B, Bravo A 2006. Leishmania and sand flies: proximity to woodland as a risk factor for infection in a rural focus of visceral leishmaniasis in west central Venezuela. Trop Med Int Health 11: 1785-1791.

Fernández MS, Salomón OD, Cavia R, Pérez AA, Acardi SA, Guccione JD 2010. Lutzomyia longipalpis spatial distribution and association with environmental variables in an urban focus of visceral leishmaniasis, Misiones, Argentina. Acta Trop 114: 81-87.

Galati EAB 2003. Morfologia, terminologia de adultos e identificação dos táxons da América. In EF Rangel, R Lainson, Flebotomíneos do Brasil, Fiocruz, Rio de Janeiro, p. 53-175.

Gontijo CMF, Melo MNM 2004. Leishmaniose visceral no Brasil: quadro atual, desafios e perspectivas. Rev Bras Epidemiol 7: 338-349.

Grimaldi G, Tesh RB 1993. Leishmaniases of the New World: current concepts and implications for future research. Clin Microbiol Rev 6: 230-250.

Grimaldi G Jr, Tech RB, McMahon-Pratt DA 1989. Review of the geographic distribution and epidemiology of leishmaniasis in the New World. Am J Trop Med Hyg 41: 687-725.

Harhay OM, Olliaro PL, Costa DL, Costa CHN 2011. Urban parasitology: visceral leishmaniasis in Brazil. Trends Parasitol 27: 403-409.

INDEC - Instituto Nacional de Estadísticas y Censos 2009. [homepage on the Internet] Precipitaciones anuales 2005-2009 [updated 1 Jan 2010; cited 25 Nov 2011]. Available from: indec.mecon.ar/ nuevaweb/cuadros/1/h010201.xls.

INDEC - Instituto Nacional de Estadísticas y Censos 2010. [homepage on the Internet] Censo Nacional de Población, Hogares y viviendas. [updated 1 Sep 2011; cited 25 Nov 2011]. Available from: censo2010.indec.gov.ar/resultadosdefinitivos.asp.

Lainson R 1989. Demographic changes and their influence on the epidemiology of the American leishmaniases. In M Service, Demography and vector borne diseases, CRC Press, Boca Raton, p. 85-106.

Lainson R, Rangel EF 2005. Lutzomyia longipalpis and the eco-epidemiology of American visceral leishmaniasis, with particular reference to Brazil - A Review. Mem Inst Oswaldo Cruz 100: 811-827. 
Mestre GLC, Fontes CJF 2007. A expansão da epidemia da leishmaniose visceral no estado de Mato Grosso, 1998-2005. Rev Soc Bras Med Trop 40: 42-48.

Mestre LAM, Aranha JMR, Esper MLP 2001. Macroinvertebrate fauna associated to the bromeliad Vriesea inflata of the Atlantic Forest (Paraná state, Southern Brazil). Braz Arch Biol Technol 44: 89-94.

Oliveira AG, Andrade Filho JD, Falcao AL, Brazil RP 2003. Estudo de flebotomíneos (Diptera, Psychodidae, Phlebotominae) na zona urbana da cidade de Campo Grande, Mato Grosso do Sul, Brasil, 1999-2000. Cad Saude Publica 19: 933-944.

Oliveira AL, Paniago AM, Dorval ME, Oshiro ET, Leal CR, Sanches M, Cunha RV, Boia MN 2006a. Foco emergente de leishmaniose visceral em Mato Grosso do Sul. Rev Soc Bras Med Trop 39: 446-450.

Oliveira CD, Diez-Roux A, Cesar CC, Proietti FA 2006b. A case-control study of microenvironmental risk factors for urban visceral leishmaniasis in a large city in Brazil, 1999-2000. Bol Oficina Sanit Panam 20: 369-376.

Quinn G, Keough M 2002. Experimental design and data analysis for biologists, Cambridge University Press, New York, 557 pp.

Rangel EF, Vilela ML 2008. Lutzomyia longipalpis (Diptera, Psychodidae, Phlebotominae) and urbanization of visceral leishmaniasis in Brazil. Cad Saude Publica 24: 2948-2952.

Salomón OD, Quintana MG 2011. Leishmaniasis y ambiente: uso de sensores remotos y sistemas de información geográfica. In
J Basualdo, R Cacchione, R Durlach, P Martino, A Seijo (eds.), Temas de zoonosis V, Asociación Argentina de Zoonosis, Buenos Aires, p. 175-188.

Salomón OD, Wilson ML, Munstermann LE, Travi BL 2004. Spatial and temporal patterns of phlebotominae sand flies (Diptera: Psychodidae) in a cutaneous leishmaniasis focus in Northern Argentina. J Med Entomol 41: 33-39.

Santini MS, Salomón OD, Acardi SA, Sandoval EA, Tartaglino LC 2010 Lutzomyia longipalpis behavior at an urban visceral leishmaniasis focus in Argentina. Rev Inst Med Trop Sao Paulo 52: 187-191.

Saraiva L, Andrade Filho JD, Falcão AL, Carvalho DAA, Margonari CS, Freitas CR, Lopes CRG, Moreno EC, Melo MN 2011. Phlebotominae fauna (Diptera: Psychodidae) in an urban district of Belo Horizonte, Brazil, endemic for visceral leishmaniasis: characterization of favored locations as determined by spatial analysis. Acta Trop 117: 137-145.

Sherlock IA 1996. Ecological interactions of visceral leishmaniasis in the state of Bahia, Brazil. Mem Inst Oswaldo Cruz 91: 671-683.

Sudia WD, Chamberlain RW 1962. Battery operated light trap, an improved model. Mosq News 22: 126-129.

Werneck GL 2008. Forum: geographic spread and urbanization of visceral leishmaniasis in Brazil. Introduction. Cad Saude Publica 24: 2937-2940

Wiens JA, Stenseth NC, Van Horne B, Ims RA 1993. Ecologycal mechanisms and landscape ecology. Oikos 66: 369-380. 